\title{
Information Transfer and the Hospital Discharge Summary: National Primary Care Provider Perspectives of Challenges and Opportunities
}

\author{
Paul M. Robelia, MD, Deanne T. Kashiwagi, MD, Sarab M. Jenkins, MS, \\ James S. Newman, MD, and Atsushi Sorita, MD, MPH
}

Purpose: The hospital discharge summary (HDS) serves as a critical method of patient information transfer between hospitalist and primary care provider (PCP). This study was designed to increase our understanding of PCP preferences for, and perceived deficiencies in, the discharge summary.

Methods: We designed a mail survey that was sent to a random sample of $\mathbf{8 0 0}$ American Academy of Family Physicians members nationally. The survey response rate was 59\%. We analyzed the availability of summaries at hospital followup, whether all desired information was contained in the summary and whether certain specific items were completed. Provider subgroup analysis was performed.

Results: The strongest predictor of discharge summary availability at posthospital followup is direct access to inpatient data. Respondents $(27.5 \%)$ had a summary available $0 \%$ to $40 \%$ of the time, $41.4 \%$ noted availability $41 \%$ to $80 \%$ of the time and $31.1 \%>80 \%$ of the time; if a provider had access to inpatient data they tended to have a discharge summary available to them $(P<.0001)$. Providers also described significant content deficits: $26.5 \%$ of providers noted the summary contained all information needed $0 \%$ to $40 \%$ of the time, $48.5 \%$ of providers noted this $41 \%$ to $80 \%$ of the time and only $25 \%$ $\mathbf{> 8 0} \%$ of the time. Specific summary items considered "very important" by providers included medication list (94\% of respondents), diagnosis list (89\%), and treatment provided (87\%).

Conclusions: Opportunities remain in timely delivery of a complete HDS to the PCP. Further multifaceted practice redesign should be directed at optimizing this critical information transfer tool, potentially encompassing electronic medical record utilization and specific training for clinicians preparing summaries. Initial efforts should focus on ensuring availability of a complete summary (containing items deemed important by PCPs including medication list, diagnosis list, and treatment provided) at the posthospital follow-up visit. (J Am Board Fam Med 2017;30:758-765.)

Keywords: Care Transition, Health Care Surveys, Health Information Technology, Hospitalists, Information Storage and Retrieval, Patient Discharge, Primary Care Physicians

Hospitalization represents a complex and high-risk part of the patient care experience. Testing and treatments take place that affect both the patient's acute illness as well as their ongoing care beyond

This article was externally peer reviewed.

Submitted 9 May 2017; revised 21 July 2017; accepted 1 August 2017.

From the Department of Family Medicine, Mayo Clinic, Rochester, MN (PMR); Division of Hospital Internal Medicine, Mayo Clinic, Rochester (DTK, JSN, AS); Department of Health Sciences Research, Mayo Clinic, Rochester (SMJ).

Funding: This study was funded by Mayo Clinic. The funding source provided logistical and analytic support including receiving the completed survey, entering data, and conducting statistical analyses. It did not have any role in the study's design or reporting. the hospital. At the same time, various pressures have accelerated the trend of inpatient care provision by hospital medicine specialists rather than primary care providers (PCPs). The knowledge gap created by this separation represents a challenging deficit with significant implications for postdischarge patient care. ${ }^{1-5}$

Consequently, the transfer of pertinent information from the inpatient to outpatient setting in a concise yet complete, relevant and expeditious way

Conflict of interest: none declared.

Corresponding author: Paul M. Robelia, MD, Department of Family Medicine, Mayo Clinic, 200 First Street SW, Rochester, MN 55905 (E-mail: Robelia.Paul@mayo.edu). 
is increasingly important. The hospital discharge summary (HDS) serves as the main conduit for information transfer between hospitalist and PCP. Although some progress has been made in improving the timely delivery of a high-quality discharge summary, such as implementing an electronic discharge summary ${ }^{6}$, opportunities remain. ${ }^{7}$ Specifically, significant numbers of care providers do not see the HDS by the time of posthospital followup ${ }^{8}$; at the same time summaries often do not include critical information. ${ }^{4}$ Receipt of a summary by the PCP before the posthospital follow-up visit, as well as inclusion of salient content in the summary, may reduce the risk of adverse events such as hospital readmissions. ${ }^{9,10}$

Some study of the interface between hospitalist and PCP has already taken place, confirming the importance of the HDS in this care transition. ${ }^{11-13}$ To further quantify specific deficits in HDS content and delivery we designed a survey of primary care physicians in the United States. Our aim was to further explore their perceptions of the ideal HDS and deficits in the current state.

\section{Methods}

This study was conducted at Mayo Clinic, Rochester, Minnesota. It was reviewed and deemed exempt by the Mayo Clinic Institutional Review Board.

\section{Survey Questionnaire and Administration}

A research group consisting of hospitalists and PCPs met to develop a questionnaire for the study group. The survey was revised in an iterative fashion and administered to group participants to estimate completion time. Questions were tailored for PCPs, asking respondents' practice demographics, use of electronic medical record, availability of inpatient data and HDS at the time of posthospital followup, and completeness of HDS content (including presence of 11 specific elements, such as medication changes, and their perceived importance by the PCP).

Primary care physicians were identified using the American Academy of Family Physicians (AAFP) mailing list; a random sample of 800 active office-based physicians (as recorded in the directory), excluding trainees, was selected. In early 2015 invitation postcards were mailed to the 800 identified physicians. Contact information and sur- vey background were provided. Subsequently a self-administered 6-page survey titled, "Perception of the Ideal Hospital Discharge Summary-A National Survey of US Physicians," was mailed to participants along with a $\$ 10$ bill. Second and third mailings were sent to nonresponders at 3-week intervals. Finally, 4 weeks after the third mailing an invitation to complete the survey online was sent to nonresponders.

Survey responses were entered by 2 separate research personnel and imported into an SAS database. The American Association for Public Opinion Research RR2 response rate definition was used. ${ }^{14}$

\section{Statistical Methods}

Primary care physician survey responses that particularly interested us included frequency of HDS availability at posthospital followup, whether all desired information was present in the summary, and whether 11 specific pieces of information were included. The frequency for each specific item being contained in the HDS was coded as 1 ("Never") to 5 (" $76 \%$ to $100 \%$ of the time"), and a total "information score" was calculated as the sum of these 11 items (possible range, 11 to 55). The survey responses were summarized with frequencies and percentages, and the information score was summarized with the median and interquartile range. All responses were included in the analysis. Further, Spearman correlations were calculated to summarize the association between specific information item frequencies with overall information frequency. The categorical parameters of interest were compared with key physician characteristics (direct access to inpatient data, years in practice, practice community size and practice setting) using nominal logistic regression models. The median information score was compared with these physician characteristics using quantile regression models. All analyses were performed using SAS version 9.4 (SAS Institute Inc., Cary, NC) or R. ${ }^{15} P$-values less than .05 were considered statistically significant.

\section{Results}

Of 800 potential respondents 474 PCPs returned surveys (response rate, 59\%). Respondent practice characteristics are listed in Table 1. 
Table 1. Self-Reported Primary Care Provider Practice Characteristics and Summary Findings

\begin{tabular}{|c|c|}
\hline & No. $(\%)^{*}$ \\
\hline \multicolumn{2}{|l|}{ Use electronic medical records } \\
\hline $\mathrm{N}$ & 471 \\
\hline Yes & $436(93)$ \\
\hline No & $35(7)$ \\
\hline \multicolumn{2}{|c|}{$\begin{array}{l}\text { Frequency of having direct access to } \\
\text { inpatient data }\end{array}$} \\
\hline $\mathrm{N}$ & 463 \\
\hline $0 \%$ to $20 \%$ of the time & $98(21)$ \\
\hline $21 \%$ to $40 \%$ & $40(9)$ \\
\hline $41 \%$ to $60 \%$ & $55(12)$ \\
\hline $61 \%$ to $80 \%$ & $96(21)$ \\
\hline $81 \%$ to $100 \%$ & $174(38)$ \\
\hline \multicolumn{2}{|c|}{$\begin{array}{l}\text { Frequency that hospital discharge summary } \\
\text { is available at followup }\end{array}$} \\
\hline $\mathrm{N}$ & 466 \\
\hline $0 \%$ to $20 \%$ of the time & $63(13.5 \%)$ \\
\hline $21 \%$ to $40 \%$ of the time & $65(13.9 \%)$ \\
\hline $41 \%$ to $60 \%$ of the time & $84(18.0 \%)$ \\
\hline $61 \%$ to $80 \%$ of the time & $109(23.4 \%)$ \\
\hline $81 \%$ to $100 \%$ of the time & $145(31.1 \%)$ \\
\hline \multicolumn{2}{|c|}{$\begin{array}{l}\text { Frequency that hospital discharge summary } \\
\text { contains all information needed }\end{array}$} \\
\hline $\mathrm{N}$ & 464 \\
\hline $0 \%$ to $20 \%$ of the time & $59(12.7 \%)$ \\
\hline $21 \%$ to $40 \%$ of the time & $64(13.8 \%)$ \\
\hline $41 \%$ to $60 \%$ of the time & $89(19.2 \%)$ \\
\hline $61 \%$ to $80 \%$ of the time & $136(29.3 \%)$ \\
\hline $81 \%$ to $100 \%$ of the time & $116(25.0 \%)$ \\
\hline \multicolumn{2}{|c|}{$\begin{array}{l}\text { Percentage of time spent on outpatient } \\
\text { primary care }\end{array}$} \\
\hline $\mathrm{N}$ & 471 \\
\hline Never & $9(2)$ \\
\hline $1 \%$ to $25 \%$ of the time & $18(4)$ \\
\hline $26 \%$ to $50 \%$ of the time & $29(6)$ \\
\hline $51 \%$ to $75 \%$ of the time & $59(13)$ \\
\hline $76 \%$ to $100 \%$ of the time & $356(76)$ \\
\hline \multicolumn{2}{|c|}{ Percentage of time spent on inpatient care } \\
\hline $\mathrm{N}$ & 465 \\
\hline Never & $263(57)$ \\
\hline $1 \%$ to $25 \%$ of the time & $159(34)$ \\
\hline $26 \%$ to $50 \%$ of the time & $29(6)$ \\
\hline $51 \%$ to $75 \%$ of the time & $6(1)$ \\
\hline $76 \%$ to $100 \%$ of the time & $8(2)$ \\
\hline \multicolumn{2}{|l|}{ Time in practice (years) } \\
\hline $\mathrm{N}$ & 473 \\
\hline 0 to 5 & $2(0)$ \\
\hline 6 to 10 & $21(4)$ \\
\hline 11 to 15 & $78(16)$ \\
\hline 16 to 20 & $101(21)$ \\
\hline 21 to 25 & $74(16)$ \\
\hline 26 to 30 & $77(16)$ \\
\hline$>30$ & $120(25)$ \\
\hline
\end{tabular}

Table 1. Continued

\begin{tabular}{lc}
\hline & No. $(\%)^{*}$ \\
\hline Practice community size & \\
$\mathrm{N}$ & 471 \\
$<5000$ people & $32(7)$ \\
5 to 20,000 & $80(17)$ \\
20 to 50,000 & $73(15)$ \\
50 to 100,000 & $74(16)$ \\
100 to 500,000 & $116(25)$ \\
$>500,000$ & $96(20)$ \\
Practice setting (multiple choice) & \\
N & 474 \\
Solo practice & $79(17)$ \\
Single specialty group & $130(27)$ \\
Multispecialty group & $85(18)$ \\
Community clinic & $31(7)$ \\
Hospital-owned clinic & $89(19)$ \\
Hospital inpatient & $6(1)$ \\
HMO & $21(4)$ \\
Academic & $41(9)$ \\
Other & $57(12)$ \\
\hline
\end{tabular}

*The number of total responses is different by question due to missing data.

HMO, Health Maintenance Organization.

Overall, availability of the HDS was variable, with $27.5 \%$ reporting availability $0 \%$ to $40 \%$ of the time, $41.4 \%$ from $41 \%$ to $80 \%$ of the time, and $31.1 \%$ more than $80 \%$ of the time. The first part of our analysis revealed that the strongest predictor of HDS availability is direct access to inpatient data by the PCP. The distribution of respondents with direct access to inpatient data were $29.8 \%$ versus $32.6 \%$ versus $37.6 \%$ for the same frequency categories noted above. If a PCP has access to inpatient data in general they tend to have a discharge summary available to them $(P<.0001)$. This finding remained significant on adjustment for community size and practice setting. In addition, we found that providers in academic practices are less likely to have discharge summaries available compared with nonacademic settings when adjusted for direct access to inpatient data, community size, and other practice setting types $(P=.02)$. When stratified by direct access to inpatient data, those in academic settings tended to have slightly lower HDS availability. In adjusted analyses, none of the other practice settings was significantly associated with this outcome (nor was community size); however, before adjustment, we found that solo practices had lower HDS availability while multispecialty group 
Table 2. Availability of Hospital Discharge Summary (HDS) by Key Characteristics (Row Percentages Shown)

\begin{tabular}{|c|c|c|c|c|c|}
\hline & \multicolumn{3}{|c|}{ Availability of HDS } & \multirow[b]{2}{*}{$P$-Value* } & \multirow[b]{2}{*}{$P$-Value } \\
\hline & $\begin{array}{l}0 \% \text { to } 40 \% \text { of the } \\
\text { Time }(\mathrm{N}=128)\end{array}$ & $\begin{array}{l}41 \% \text { to } 80 \% \text { of the } \\
\text { Time }(\mathrm{N}=193)\end{array}$ & $\begin{array}{l}81 \% \text { to } 100 \% \text { of the } \\
\text { Time }(\mathrm{N}=145)\end{array}$ & & \\
\hline Direct access to inpatient data & & & & $<.0001$ & $<.0001$ \\
\hline $0 \%$ to $40 \%$ of the time & $91(65.9 \%)$ & $40(29.0 \%)$ & $7(5.1 \%)$ & & \\
\hline $41 \%$ to $80 \%$ of the time & $30(19.9 \%)$ & $109(72.2 \%)$ & $12(7.9 \%)$ & & \\
\hline $81 \%$ to $100 \%$ of the time & $5(2.9 \%)$ & $43(24.7 \%)$ & $126(72.4 \%)$ & & \\
\hline Community size & & & & .79 & .15 \\
\hline$\leq 20,000$ & $34(30.6 \%)$ & $39(35.1 \%)$ & $38(34.2 \%)$ & & \\
\hline 20,001 to 100,000 & $40(27.8 \%)$ & $60(41.7 \%)$ & $44(30.6 \%)$ & & \\
\hline 100,001 to 500,000 & $30(26.1 \%)$ & $53(46.1 \%)$ & $32(27.8 \%)$ & & \\
\hline$>500,000$ & $24(25.5 \%)$ & $39(41.5 \%)$ & $31(33.0 \%)$ & & \\
\hline \multicolumn{6}{|l|}{ Practice type } \\
\hline Solo & & & & .0003 & .58 \\
\hline No & $92(23.8 \%)$ & $166(42.9 \%)$ & $129(33.3 \%)$ & & \\
\hline Yes & $36(45.6 \%)$ & $27(34.2 \%)$ & $16(20.3 \%)$ & & \\
\hline Single-specialty group & & & & .28 & .68 \\
\hline No & $87(25.8 \%)$ & $139(41.2 \%)$ & $111(32.9 \%)$ & & \\
\hline Yes & $41(31.8 \%)$ & $54(41.9 \%)$ & $34(26.4 \%)$ & & \\
\hline Multi-specialty group & & & & .007 & .82 \\
\hline No & $115(30.2 \%)$ & $157(41.2 \%)$ & $109(28.6 \%)$ & & \\
\hline Yes & $13(15.3 \%)$ & $36(42.4 \%)$ & $36(42.4 \%)$ & & \\
\hline Hospital-owned office-based & & & & .049 & .73 \\
\hline No & $112(29.7 \%)$ & $155(41.1 \%)$ & $110(29.2 \%)$ & & \\
\hline Yes & $16(18.0 \%)$ & $38(42.7 \%)$ & $35(39.3 \%)$ & & \\
\hline Academic & & & & .09 & $.02^{\S}$ \\
\hline No & $117(27.5 \%)$ & $182(42.7 \%)$ & $127(29.8 \%)$ & & \\
\hline Yes & $11(27.5 \%)$ & $11(27.5 \%)$ & $18(45.0 \%)$ & & \\
\hline Other $^{\ddagger}$ & & & & .23 & .56 \\
\hline No & $102(27.9 \%)$ & $144(39.5 \%)$ & $119(32.6 \%)$ & & \\
\hline Yes & $26(25.7 \%)$ & $49(48.5 \%)$ & $26(25.7 \%)$ & & \\
\hline
\end{tabular}

*Unadjusted $P$-value $\left(\chi^{2}\right.$ test).

${ }^{\dagger}$ Adjusted $P$-value from nominal logistic regression model including all predictors listed in this table.

${ }^{\ddagger}$ Community clinic, hospital inpatient, group staff HMO, or other.

${ }^{\S}$ When stratified according to direct access to inpatient data, there is slightly less availability of the HDS among those in academic settings (see Table 3).

HMO, Health Maintenance Organization.

and hospital-owned office-based practices had higher HDS availability. These results are outlined in Table 2 and Table 3.
Our next analysis examined responses to the question, "How often does the discharge summary you receive contain all the information you need

Table 3. Hospital Discharge Summary (HDS) Availability in Academic Versus Non-Academic Settings

\begin{tabular}{|c|c|c|c|c|c|c|}
\hline \multirow[b]{3}{*}{ Availability of HDS } & \multicolumn{6}{|c|}{ Direct Access to Inpatient Data } \\
\hline & \multicolumn{2}{|c|}{$0 \%$ to $40 \%$} & \multicolumn{2}{|c|}{$41 \%$ to $80 \%$} & \multicolumn{2}{|c|}{$81 \%$ to $100 \%$} \\
\hline & Non-academic & Academic & Non-academic & Academic & Non-academic & Academic \\
\hline $0 \%$ to $40 \%$ of the time & $85(64 \%)$ & $6(100 \%)$ & $26(18 \%)$ & $4(50 \%)$ & $4(3 \%)$ & $1(4 \%)$ \\
\hline $41 \%$ to $80 \%$ of the time & $40(30 \%)$ & & $105(73 \%)$ & $4(50 \%)$ & $36(24 \%)$ & $7(27 \%)$ \\
\hline $81 \%$ to $100 \%$ of the time & $7(5 \%)$ & & $12(8 \%)$ & & $108(73 \%)$ & $18(69 \%)$ \\
\hline $\operatorname{Total}(\mathrm{N})$ & $132(100 \%)$ & $6(100 \%)$ & $143(100 \%)$ & $8(100 \%)$ & $148(100 \%)$ & $26(100 \%)$ \\
\hline
\end{tabular}


Figure 1. Discharge summary information inclusion and perceived importance. HDS, Hospital Discharge Summary.

\section{Frequency HDS Contains Information}
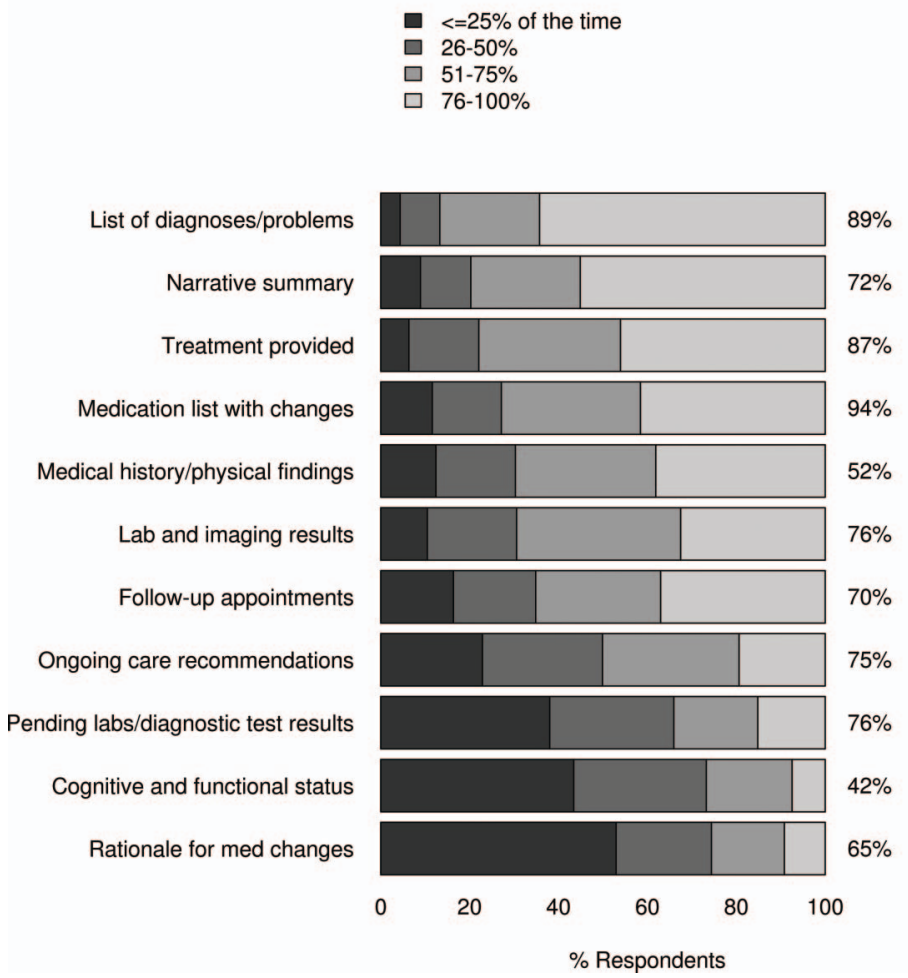

for follow-up care?" as they relate to frequency of inclusion of 11 specific pieces of information. These items were presented in a follow-up survey question and included diagnosis and problem list, lab and imaging results, rationale for medication changes, ongoing care recommendations and additional items as detailed in Figure 1. Overall, only $25 \%$ of respondents reported that the HDS contained all information needed more than $80 \%$ of the time, whereas $48.5 \%$ noted this $41 \%$ to $80 \%$ of the time and $26.5 \%$ described $40 \%$ of the time or less. Among the 11 pieces of information, the most commonly reported in the HDS was a list of diagnoses/problems, and the least reported was the rationale for medication changes. We found that, in general, more favorable responses to the overall question were highly associated with the frequency of specific pieces of information being present in the summary (all $P<.0001$ ). Although correlations (Spearman) between each specific item with the overall information question were between 0.44 to 0.58 , the most correlated piece of information was "ongoing care recommendations" (correlation = 0.58 ), and the lowest correlation was with "cognitive and functional status at discharge" and "med- ication list with changes" (correlation with each $=$ 0.44). Survey recipients were also asked about the importance level for each of these specific pieces of information. Each item was regarded as either "somewhat important" or "very important" by most survey respondents, with very few responding in the other categories ("neither important nor not important," "somewhat unimportant," or "very unimportant"). "Medication list with changes" was regarded as most important (94\% "very important"), followed by "list of diagnoses/problems" (89\%) and "treatment provided" (87\%). "Cognitive and functional status" was least important (42\% noting this as "very important"). These results are summarized in Figure 1.

As a summary measure of the 11 specific pieces of information examined above, we calculated an "information score" (see Statistical Methods). Overall, the median score was 40 , which aligns with information being contained in the HDS roughly half of the time (falling between categories $26 \%$ to $50 \%$ and $51 \%$ to $75 \%$ of the time), with interquartile range of 34 to 47 . We found that higher scores were significantly associated with more direct access to inpatient data $(P<.0001)$, and that hospital- 
owned clinic practices tended to have lower scores $(P=.008)$ in a model adjusted for access to inpatient data, community size, and practice setting.

\section{Discussion}

The results of this national provider survey reveal that PCPs who have access to hospital data are more likely to have a HDS available to them at the time of posthospital followup. On a superficial level this finding seems self confirmatory; that is, if a PCP has access to hospital records he or she is more likely to have an available hospital summary. The known logistic barriers of correct PCP identification and use of mail, fax, or e-mail ${ }^{8}$ are removed (our finding that solo practitioners have lower HDS availability than other practice types may indicate that these issues persist for some). However, even for PCPs with direct access to inpatient data $>80 \%$ of the time, only $72.4 \%$ had an available HDS $>80 \%$ of the time. Hospital requirements regarding the timing of HDS preparation vary widely; presumably this gap largely relates to noncompletion of the summary by the time of the posthospital follow-up visit, but further study of other potential barriers could provide additional insight. Critically, only a quarter of respondents reported that the HDS contained all information needed more than $80 \%$ of the time, and a quarter $40 \%$ of the time or less. Technological solutions such as shared electronic medical records may remedy some of the challenges of HDS availability, but issues of timely preparation and inclusion of relevant content remain. ${ }^{4,9,16-18}$

Previous studies have shown that many physician trainees feel unprepared to write discharge summaries ${ }^{13}$, and that academic medical centers may trail other practice settings in the timely provision of complete summaries. ${ }^{1,16}$ The relatively small number of responses within the academic practice subgroup $(n=40)$ limits our ability to draw strong conclusions; however, the finding that PCPs in academic settings tend to be slightly less likely to have the HDS available at posthospital followup (when adjusted for direct access to inpatient data) offers some validation that this issue lingers. Although our survey did not address potential causative factors, differential utilization of electronic medical records in academic centers, conflicting priorities for learners and teachers (ie, not viewing documentation preparation as a learn- ing experience) and time pressure (resulting from duty hour limitations and other educational commitments) may contribute to this result. Future study focusing on the academic practice setting could help clarify this question and strengthen the validity of conclusions. In addition, Figure 1 summarizes the perceived importance of discharge summary components by PCPs; $>80 \%$ reported "list of diagnosis and problems," "treatment provided," and "medication list with changes" as "very important." All 11 components were felt to be "somewhat important" or "very important" by $>80 \%$ of PCPs. Further study of training and workflow optimization for learners, particularly as they relate to preparation of discharge summaries that include this high-yield content, could offer considerable benefit for patients and caregivers at academic centers as well as those in communities served by graduates.

In a model adjusted for access to inpatient data, community size, and practice setting the HDS "information score" (a reflection of whether specific desired information was contained in the summary) was found to be higher with more direct access to inpatient data. This may reflect automated HDS templates active within integrated systems or information recall errors in which PCPs access the desired information outside the HDS but do not recall this distinction at survey completion. Hospital-owned clinic practices tended to have lower information scores, possibly due to reliance on automated systems or hospitalist assumptions that PCPs use information sources outside the HDS.

Our study's findings are strengthened by engagement of providers at the national level and a favorable response rate. Table 1 demonstrates broad representation by providers at various levels of experience across multiple practice and community settings, which will enhance the generalizability of these results. In addition, given that responses to the single question asking how often the discharge summary contains all information needed for follow-up care are associated with the frequency of specific pieces of information being contained in the summary we can infer validation of adequate performance for this survey question.

Limitations of our study include sampling bias; the use of a society-specific database potentially restricts our ability to generalize conclusions beyond the demographic profiles and practice preferences of AAFP members. However, the influence 
of this bias should be minimized by the broad membership of AAFP (approximately 125,000 members in the United States). In addition, nonresponse bias could favor the perspectives of providers who are more able and willing to complete surveys. PCPs who encounter barriers to HDS availability and instead obtain pertinent information directly from the patient could be disproportionately represented as well. Our favorable response rate, as well as the wide demographic profile of our respondents, should mitigate these effects. This survey was administered in 2015; continued implementation and refinement of electronic medical record systems could conceivably have improved HDS content and availability in the interim, but the deficits identified in our results are unlikely to have been wholly remedied since that time. This survey was limited to physicians. Inpatient and outpatient care teams increasingly incorporate Nurse Practitioners and Physician Assistants as core members; these groups, with unique perspectives stemming from alternate training and scope of practice models, may offer additional insights. Finally, the survey did not address specific barriers to availability of inpatient data and the HDS (such as conservative interpretation of protected health information sharing guidelines by hospital systems). Further study of contributing factors may aid practice redesign and enhance information access.

The HDS serves as the main conduit for communication between inpatient and outpatient care teams. More broadly, previous study has shown that increased communication between PCPs and specialists, using health information technology tools such as electronic health records, reduces hospitalizations. ${ }^{19}$ Focusing on the posthospital care transition, complete and available summaries have been shown to reduce hospital readmission risk. ${ }^{10}$ Despite this recognition, our survey demonstrates that PCPs continue to identify deficits in HDS content and availability; although having access to inpatient medical data increases the likelihood that a clinician will have the HDS available to them, a high level of deficiency in desired content remains. In this age of practice redesign and electronic medical record deployment, our findings suggest that initial efforts should include ensuring availability of a complete summary (containing items deemed important by PCPs including diagnosis list, treatment provided, and medication list) at the posthospital follow-up visit. Improved outcomes during and af- ter this critical care transition will be a result welcomed by both patients and their care providers.

We thank Jon C. Tilburt, MD, Division of General Internal Medicine, Department of Internal Medicine, Mayo Clinic, for guidance and advice on survey design and implementation. We also thank Ivana T. Croghan, PhD, Division of Primary Care Internal Medicine, Department of Internal Medicine, Mayo Clinic, for guidance on research design and analytic support.

To see this article online, please go to: http://jabfm.org/content/ 30/6/758.full.

\section{References}

1. Gandara E, Moniz TT, Ungar J, et al. Deficits in discharge documentation in patients transferred to rehabilitation facilities on anticoagulation: Results of a systemwide evaluation. Jt Comm J Qual Patient Saf 2008;34:460-463.

2. Harel Z, Wald R, Perl J, Schwartz D, Bell CM. Evaluation of deficiencies in current discharge summaries for dialysis patients in Canada. J Multidiscip Healthc 2012;5:77-84.

3. Kattel S, Manning DM, Erwin PJ, Wood H, Kashiwagi DT, Murad MH. Information transfer at hospital discharge: A systematic review. J Patient Saf 2016 Jan 7 [Epub ahead of print].

4. Kripalani S, et al. Deficits in communication and information transfer between hospital-based and primary care physicians: implications for patient safety and continuity of care. JAMA 2007;297:831-841.

5. O'Leary KJ, Liebovitz DM, Feinglass J, Liss DT, Baker DW. Outpatient physicians' satisfaction with discharge summaries and perceived need for an electronic discharge summary. J Hosp Med 2006;1:317320.

6. O'Leary KJ, Liebovitz DM, Feinglass J, et al. Creating a better discharge summary: Improvement in quality and timeliness using an electronic discharge summary. J Hosp Med 2009;4:219-225.

7. Bell CM, Schnipper JL, Auerbach AD, et al. Association of communication between hospital-based physicians and primary care providers with patient outcomes. J Gen Intern Med 2009;24:381-386.

8. van Walraven C, Seth R, Austin PC, Laupacis A. Effect of discharge summary availability during postdischarge visits on hospital readmission. J Gen Intern Med 2002;17:186-192.

9. Hoyer EH, Odonkor CA, Bhatia SN, et al. Association between days to complete inpatient discharge summaries with all-payer hospital readmissions in Maryland. J Hosp Med 2016;11:393-400.

10. Salim Al-Damluji M, Dzara K, Hodshon B, et al. Association of discharge summary quality with readmission risk for patients hospitalized with heart failure exacerbation. Circ Cardiovasc Qual Outcomes 2015;8:109-111. 
11. Hesselink G, Schoonhoven L, Barach P, et al. Improving patient handovers from hospital to primary care: A systematic review. Ann Intern Med 2012;157: 417-428.

12. Tang, N. A primary care physician's ideal transitions of care-Where's the evidence? J Hosp Med 2013; 8:472-477.

13. Yemm R, Bhattacharya D, Wright D, Poland F. What constitutes a high quality discharge summary? A comparison between the views of secondary and primary care doctors. Int J Med Educ 2014;5:125-131.

14. American Association for Public Opinion Research. Standard definitions: Final dispositions of case codes and outcome rates for surveys. 9th ed. 2016. Available from: http://www.aapor.org/Standards-Ethics/ Standard-Definitions-(1).aspx.

15. Team, R.C., R: A language and environment for statistical computing. In: R Foundation for Statistical
Computing. Vienna, Austria; 2014. Available from: http://www.R-project.org.

16. Horwitz LI, Jenq GY, Brewster UC, et al. Comprehensive quality of discharge summaries at an academic medical center. J Hosp Med 2013;8:436-443.

17. van Walraven C, Duke SM, Weinberg AL, Wells PS. Standardized or narrative discharge summaries. Which do family physicians prefer? Can Fam Physician 1998;44:62-69.

18. van Walraven C, Rokosh E. What is necessary for high-quality discharge summaries? Am J Med Qual 1999;14:160-169.

19. O'Malley AS, Reschovsky JD, Saiontz-Martinez C. Interspecialty communication supported by health information technology associated with lower hospitalization rates for ambulatory care-sensitive conditions. J Am Board Fam Med 2015;28:404-417. 